\title{
Nordic TCFD workshop Key takeaways and recommendations
}

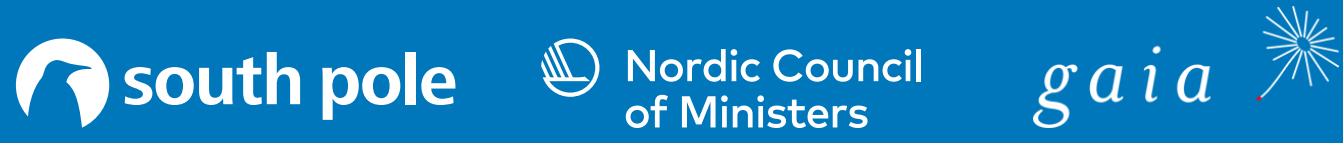




\section{Part 1. Introduction and webinars}

The Nordic countries have set ambitious climate goals (see table below) and want to become the most sustainable and integrated region in the world in 2030. These commitments are enshrined in the Nordic Vision 2030, the Nordic Prime Minister's Declaration on Nordic Climate Neutrality, and the Helsinki Principles through the Coalition of Finance Ministers for Climate Action.

\begin{tabular}{ll}
\hline Denmark & 2050: Zero net emissions \\
\hline Sweden & 2045: Zero net emissions \\
\hline Norway & 2030: Climate neutrality \\
\hline Finland & 2035: Zero net emissions \\
\hline lceland & 2040: Carbon neutrality \\
\hline
\end{tabular}

* Note that the roadmaps and the definitions of carbon neutrality vary between the countries. Find more information and recommendations on activities where the Nordic countries could cooperate here.

In order to address the climate challenge, the Nordic Platform for Mobilising Climate Finance, led by South Pole in collaboration with Gaia Consulting, has brought together Nordic public and private sector actors for in-depth discussions on innovative and efficient ways to mobilise climate finance.
During the autumn of 2020, the platform brought together Nordic companies, investors, civil society organisations, international sustainability organisations and others, for two series of tailored webinars. During the webinars the most prevalent climate-related private sector topics - including ambitions, challenges, and what measures are required from the Nordic governments -were discussed.

The webinar findings showed that the Nordic private sector is ready to lead in the climate transition, and that there is a role for the Nordic Governments to facilitate this transition. The key findings are shown below, and the published summary can be accessed here. The findings showed that:

- there is a need for standardisation of climate data, and improved data availability.

- there is a need for platforms that provide a non-competitive environment to share knowledge and good practices.

- a common climate reporting framework is required, but there is no need to reinvent the wheel. Instead, the focus should lie on improving and standardising an existing framework, such as TCFD.

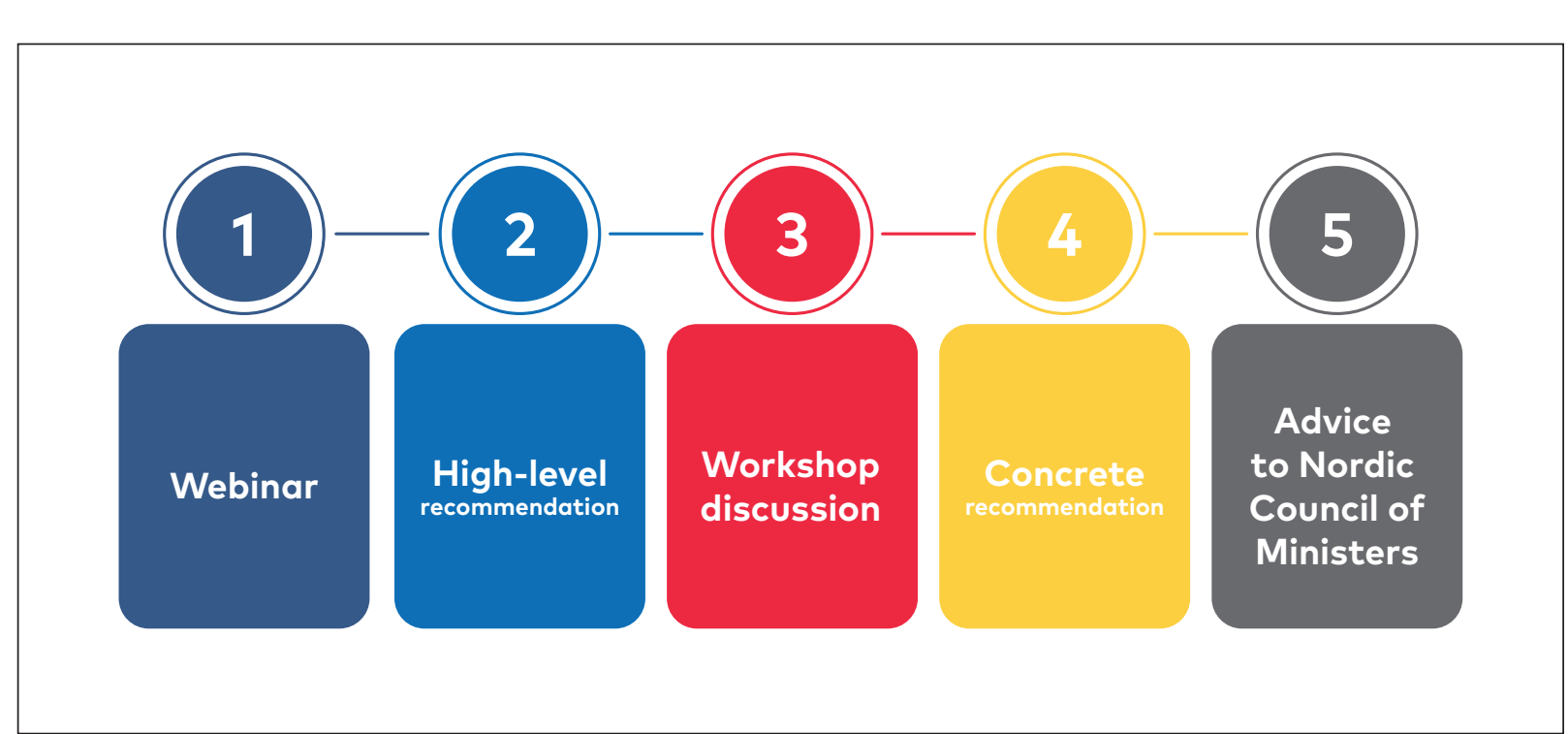




\section{Part 2. Digital workshop}

In order to continue stakeholder discussion on this topic, and to deepen the understanding and allow the formulation of recommendations for Nordic governments, a workshop discussion was organised in the spring of 2021. The central question was: "what could the role of the Nordic governments be in facilitating TCFD or other climate frameworks?" Following are the key takeaways from the workshop, which act as a basis for the advice to the Nordic Council of Ministers.

\section{Key recommendations}

The workshop discussion provided an occasion to test the findings and recommendations from the webinar series, and to refine and complement insights from previous stakeholder discussions. It confirmed the overall conclusion that the Nordic governments can and should take an important role - as an enabler as well as an actor and accelerator of required climate action - at national, Nordic and international levels. Below are the key recommendations:

\section{Be a private sector knowledge partner. Nordic} countries should accelerate the uptake of TCFD through knowledge dissemination, support and awareness raising.

- Nordic countries should harness their joint Nordic capacities in knowledge dissemination, support and awareness raising.

- The recommendation is to establish and host a 2-5 year platform that shares good practices, technical guidance and lessons learned on TCFD implementation, including scenario analysis, in a regional context. It could draw inspiration from the Climate Financial Risk Forum in the UK and the Climate Measurements Standards Initiative in Australia where industry experts, regulators and the scientific community are involved a.
- The platform could serve not only as a TCFD hub, but also as a wider EU Taxonomy knowledge centre. It should aim to provide guidance and clarity on the main EU Taxonomy elements as intended by the TEG such as SC (Substantial Contribution), DNSH (Do No Significant Harm) and (MSS) Minimum Social Safeguards as a potential area of Nordic value-add.

Publicly endorse and establish the foundations for climate data and metrics. Nordic countries should address challenges on climate-related data and standardisation through research.

- The private sector is appreciative of clear governmental endorsement and guidance on addressing climate change. While being closely involved in international platforms and initiatives such as the NGFS and / or IPSF, Nordic governments can also facilitate Nordic research and development efforts on data constraints and standardisation needs.

- Areas where joint Nordic action could add value include e.g. promotion of climate scenarios and reduction pathways, regionally adapted best-practice guidance and shared data resources for Scope 3 GHG calculations, as well as efficient and fair carbon pricing.

\section{Get your own houses into order and establish private sector partnerships.}

- While decisions concerning the ESG regulatory environment are taken on EU level or at international fora, opportunities to align Nordic public finance flows through national governmental decision-making are readily available. There are an increasing number of Nordic governmental initiatives on ESG-aligned budgeting, ownership steering and public procurement processes. There is, however, room to raise the level of ambition and more systematically: 
- Assess operational emissions including scope 3

- Formulate a sustainability strategy and set targets

- Transparent reporting of government income and integrate ESG factors into public procurement and financing

All the Nordic countries have some type of strategy on sustainable public procurement (e.g. Sweden), however, continuous efforts are needed to ensure the adoption and implementation of these. MAPS was developed by the World Bank and DAC and allows countries to assess their public procurement in line with the SDGs. It has so far been tested on Norway (in the Nordics).

- Publish government-level TCFD reports in the Nordic countries.

The Bank of England and the National Bank of Canada released their first climate-related financial disclosures in 2020. Furthermore, the TCFD status report 2020 states that eight national governments and over 110 regulators and governmental entities worldwide support the TCFD.

- National central banks and financial supervisory authorities can help accelerate the transformation of the finance sector. National financial institutions, pension funds, as well as joint Nordic financial institutions (NEFCO, NIB, NDF) as well as Nordic-wide Development Finance Institutions (Norfund, Swedfund, IFU and Finnfund) represent direct opportunities for Nordic governments to show leadership.

\section{Part 3. Final report}

The recommendations in the final report can serve the Nordic governments and the Nordic Council of Ministers to further deliberate how to accelerate climate action and how to enhanceNordic valueadded through continued collaboration. Beyond the recommendations from the webinar series and the workshop hosted under the Nordic Platform for Mobilising Climate Finance, the Nordics have a successful history of policy coordination. It goes without saying that this tradition of speaking on selected themes with a 'joint Nordic voice' on international fora can further help accelerate the mobilisation of finance for low-carbon, climate resilient transformations in the Nordics and internationally.

\section{Acronyms and abbreviations}

\begin{tabular}{ll}
\hline DAC & Development Assistance Committee \\
\hline DNSH & Do no significant harm \\
\hline ESG & Environmental, social and governance \\
\hline IPSF & European Union \\
\hline MAPS & $\begin{array}{l}\text { Methodology for Assessing } \\
\text { Procurement Systems }\end{array}$ \\
\hline MSS & Minimum Social Safeguards \\
\hline NGFS & $\begin{array}{l}\text { Network for Greening the Financial } \\
\text { System }\end{array}$ \\
\hline SC & Substantial Contribution \\
\hline SDGs & Sustainable Development Goals \\
\hline TCFD & $\begin{array}{l}\text { Task Force on Climate-related } \\
\text { Financial Disclosures }\end{array}$ \\
\hline
\end{tabular}

